\title{
Conagenin Derived from Streptomyces roseosporus Enhances
}

\section{Macrophage Functions}

\author{
MASAFUMt HAMADA*,a, Eiko SONOTAKE, \\ Shigeru YAMAMOTO ${ }^{a}$ and SATORU Moriguchi ${ }^{b}$ \\ ${ }^{a}$ Department of Nutrition, School of Medicine, The University of Tokushima, \\ Tokushima 770-8503, Japan \\ ${ }^{\mathrm{b}}$ Department of Nutrition, Faculty of Human Life Science, Yamaguchi Preferectural University, \\ Yamaguchi 753-8502, Japan
}

(Received for publication March 18, 1999)

\begin{abstract}
In contrast to the studies that describes the effects of conagenin $(\mathrm{CNG})$ on the cellular immunity of lymphocytes (references), we investigated the in vitro effect of CNG on macrophage function. Phagocytosis of alveolar macrophages (AM) against opsonized-sheep red blood cells (SRBC) was significantly enhanced following in vitro incubation with CNG for 12 hours at $37^{\circ} \mathrm{C}$, which was closely associated with increased expression of Fc-receptor in AM membranes. Macrophage-activating factor (MAF), prepared from splenic lymphocytes in vitro stimulated with concanavarin A (Con A) for 48 hours at $37^{\circ} \mathrm{C}$, had also the enhancing effect on phagocytosis of AM against opsonized-SRBC. Preincubation with CNG $(0.1 \mu \mathrm{g} / \mathrm{ml})$ and MAF $(1 / 100$ dilution) induced the additional effect on phagocytosis of $\mathrm{AM}$, which was associated with the increased expression of Fc-receptor in $\mathrm{AM}$ membranes. These results suggest that $\mathrm{CNG}$ enhances $\mathrm{AM}$ phagocytosis by increasing the expression of $\mathrm{Fc}$-receptor on their membranes via either effecting different sub-populations of AM cells or by activating independent mechanism on the same AM cell population.
\end{abstract}

Conagenin ( $\mathrm{CNG} ; \mathrm{C}_{10} \mathrm{H}_{19} \mathrm{NO}_{6}$, MW 249.16) extracted from Streptomyces roseosporus is known to be immunoenhancer. CNG enhances the incorporation of $\left[{ }^{3} \mathrm{H}\right]$-thymidine by splenic lymphocytes following in vitro stimulation with Con $\mathrm{A}^{1)}$. In addition, $\mathrm{CNG}$ enhances production of cytokines such as interleukin-2, 3 and $6^{2,3)}$. Although natural killer cell (NK) activity is known to decrease in tumor-bearing mice, the administration of CNG did not induce the decrease of NK activity and maintained NK activity at the normal level ${ }^{3)}$. Until now, most of studies on the effect of CNG on cellular immunity has focused on lymphocyte functions. In this study the in vitro effect of CNG on macrophage function is discussed.

\section{Materials and Methods}

Animals

Male F344 rats, 8 weeks old, were obtained from Japan SLC (Shizuoka, Japan) and maintained under specific pathogen-free conditions at $21 \pm 2^{\circ} \mathrm{C}$ and $55 \pm 5 \%$ humidity.

\section{$\mathrm{CNG}$}

CNG was gifted from KANEKA Co., Ltd. (Osaka, Japan), and dissolved in culture medium and filtered through a $0.22 \mu \mathrm{m}$ Millipore membrane (Millipore Corp, Bedford, MA).

\section{Cell Preparation}

Rats were anesthetized with pentobarbital sodium $(0.1 \mathrm{ml} / 100 \mathrm{~g} \mathrm{BW})$ and exanguinated by cutting off the arteries of both kidneys. Then, AM were collected by 
bronchoalveolar lavage with saline. AM were collected by centrifugation. Collected AM were resuspended with RPMI 1640 medium including $10 \%$ fetal bovine serum (FBS) and antibiotics such as penicillin (100 units/ml) and streptomycin $(100 \mu \mathrm{g} / \mathrm{ml})$.

\section{Macrophage-activating Factor (MAF)}

Spleens from rats were aseptically removed and minced. Then, splenocytes were passed through a stainless steel mesh in medium. They were adjusted at $1 \times 10^{7} / \mathrm{ml}$ and then incubated with $5 \mu \mathrm{g} / \mathrm{ml}$ Con A-sepharose for 48 hours at $37^{\circ} \mathrm{C}$. After incubation, the supernatants were filtered through a $0.22 \mu \mathrm{m}$ Millipore membrane and stored at $-80^{\circ} \mathrm{C}$ until the experiment. This supernatant was diluted with RPMI 1640 culture medium and used as MAF.

\section{Phagocytosis of AM}

Sheep red blood cells (SRBC) (Nihon Biotest, Tokyo) were washed 3 times with RPMI-1640. Opsonization was accomplished by incubating $10 \mathrm{ml}$ of washed SRBC with $0.2 \mathrm{ml}$ of rat anti-SRBC antiserum (heat-inactivated) for 1 hour at $37^{\circ} \mathrm{C}$, and then they were washed 3 times with medium. Radioactive labeling of opsonized-SRBC was accomplished by incubating with $0.2 \mathrm{ml}$ of $\mathrm{Na}_{2}{ }^{51} \mathrm{CrO}_{4}$ (Amersham) for 1 hour at $37^{\circ} \mathrm{C}$. Labeled opsonized$\mathrm{SRBC}$ were washed 3 times to remove excess ${ }^{51} \mathrm{Cr}$, and the final volume was adjusted to $0.6 \%$ suspension of SRBC. AM were adjusted $\left(6 \times 10^{5} / \mathrm{ml}\right)$ and plated $\left(3 \times 10^{5} /\right.$ well $)$ in 24 well flat-bottom microplate. After 1 hour, the plate was washed with medium to remove nonadherent cells, and then various concentrations of CNG $(0 \sim 100 \mu \mathrm{g} / \mathrm{ml})$ and/or diluted-MAF were added to each well and incubated for 12 hours at $37^{\circ} \mathrm{C}$. After incubation, plates were washed with medium, added ${ }^{51} \mathrm{Cr}$-labeled opsonized-SRBC, and incubated for 1 hour at $37^{\circ} \mathrm{C}$. The cultures were rinsed once with distilled water to lyse nonphagocytosed SRBC, and then washed twice with physiological saline. All remaining adherent cells were lysed by $0.1 \mathrm{~N} \mathrm{NaOH}$, and the radioactivity of lysate was measured by gamma counter.

\section{Fc-receptor Expression in AM Membrane}

AM were incubated with ${ }^{51} \mathrm{Cr}$-labeled opsonizedSRBC for 1 hour at $4^{\circ} \mathrm{C}$. Then, the culture plate was washed 4 times with physiological saline at $4^{\circ} \mathrm{C}$. All remaining cells were lysed by $0.1 \mathrm{~N} \mathrm{NaOH}$, and the radioactivity of lysate was measured by gamma counter.
Fig. 1. Phagocytosis of ${ }^{51} \mathrm{Cr}$-opsonized SRBC by AM following in vitro incubation with various concentrations of $\mathrm{CNG}(0 \sim 100 \mu \mathrm{g} / \mathrm{ml})$.

$* p<0.05, * * p<0.01$ (vs. without CNG).

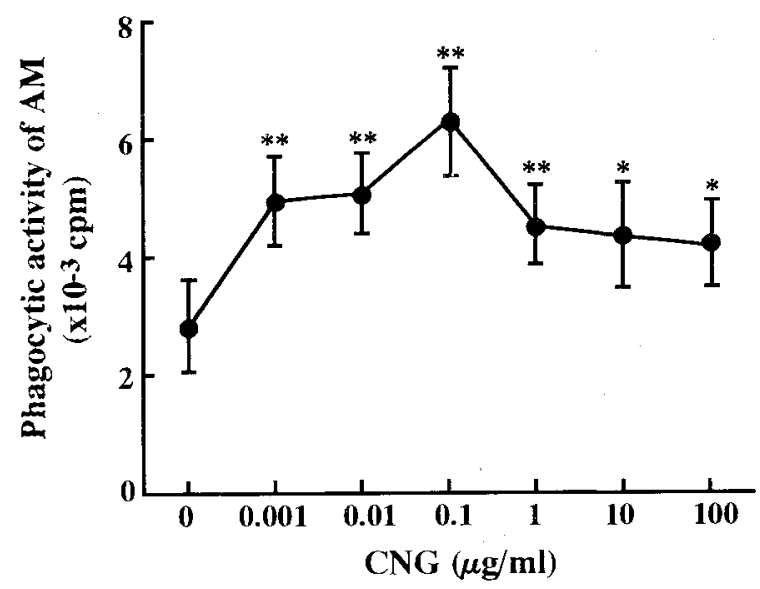

Statistical Analysis

Statistical significance was analyzed by Student's $t$-test.

\section{Results}

Phagocytosis of Opsonized-SRBC by AM

AM were preincubated with various concentrations of CNG $(0 \sim 100 \mu \mathrm{g} / \mathrm{ml})$ for 12 hours at $37^{\circ} \mathrm{C}$, and then phagocytic activity of $\mathrm{AM}$ were determined by using ${ }^{51} \mathrm{Cr}$-labeled opsonized SRBC. Phagocytic activity of AM was significantly increased by in vitro incubation with all concentrations of $\mathrm{CNG}$ (Fig. 1). The most effective concentration of $\mathrm{CNG}$ to enhance $\mathrm{AM}$ phagocytosis was $0.1 \mu \mathrm{g} / \mathrm{ml}$, which showed 2 times higher phagocytosis compared to AM cultured with medium alone.

Fc-receptor Expression in AM Membrane

AM were preincubated with $\mathrm{CNG}$ for 12 hours at $37^{\circ} \mathrm{C}$, and then $\mathrm{Fc}$-receptor expression in $\mathrm{AM}$ was examined after incubation with opsonized-SRBC for 1 hour at $4^{\circ} \mathrm{C}$. $\mathrm{Fc}-$-receptor expression in $\mathrm{AM}$ was significantly increased by in vitro incubation with CNG. Both 0.01 and $0.1 \mu \mathrm{g} / \mathrm{ml}$ of $\mathrm{CNG}$ induced 2.5-fold increase compared to that incubated with medium alone (Fig. 2). However, the concentration of $\mathrm{CNG}$ did not induce a further increase of FC-receptor expression of AM. 
Fig. 2. Fc-receptor expression in AM membrane following in vitro incubation with various concentrations of $\mathrm{CNG}(0 \sim 100 \mu \mathrm{g} / \mathrm{ml})$.

$* p<0.05$ (vs. without CNG)

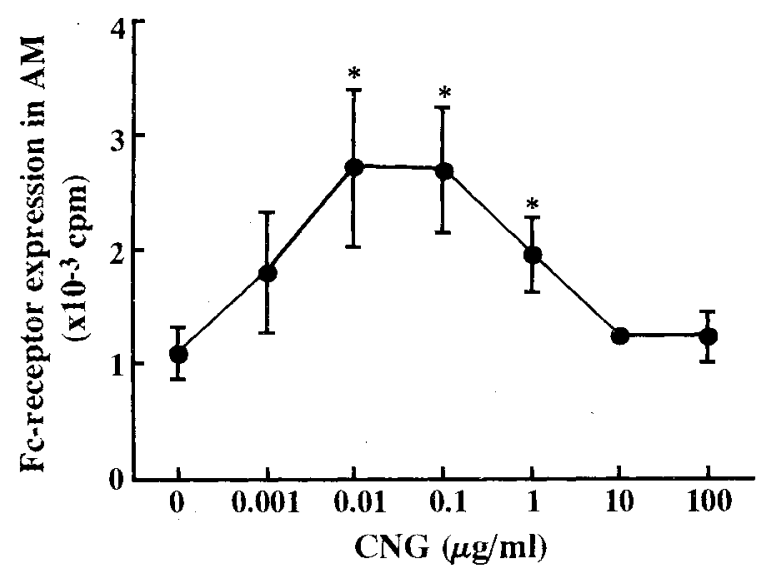

Fig. 3. In vitro effect of MAF on phagocytic activity of AM.

${ }^{*} p<0.05,{ }^{* *} p<0.01$ (vs. medium alone).

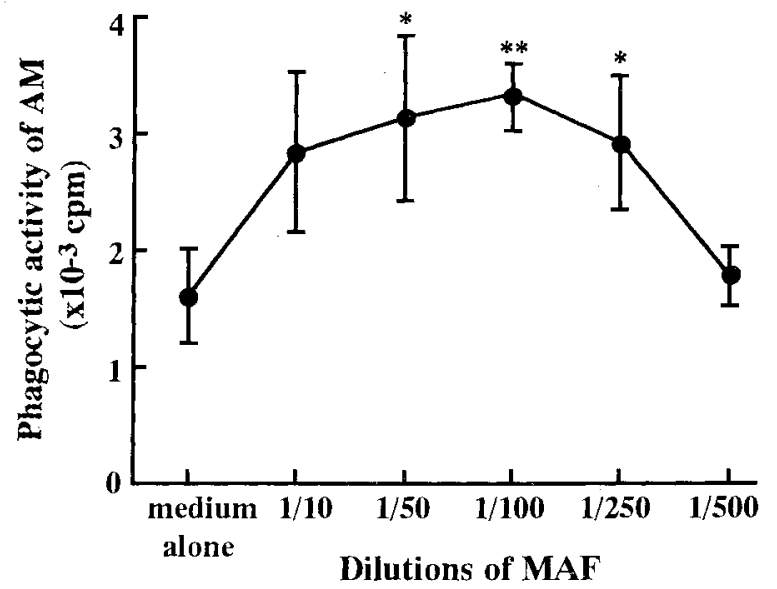

Phagocytic Activity of AM after MAF Treatment

Phagocytic activity of AM against opsonized-SRBC was also significantly enhanced by in vitro incubation with MAF (Fig. 3). The highest enhancement of AM phagocytosis was shown in the dilution of MAF at the ratio of $1: 100$.
Fig. 4. Phagocytosis of ${ }^{51} \mathrm{Cr}$-opsonized SRBC by $\mathrm{AM}$ following in vitro incubation with $\mathrm{CNG}$ $(0.1 \mu \mathrm{g} / \mathrm{ml})$ and/or MAF (1/100 dilution).

${ }^{*} p<0.05$ ( $v s$. medium alone); ${ }^{*} p<0.05$ ( $v$. MAF).

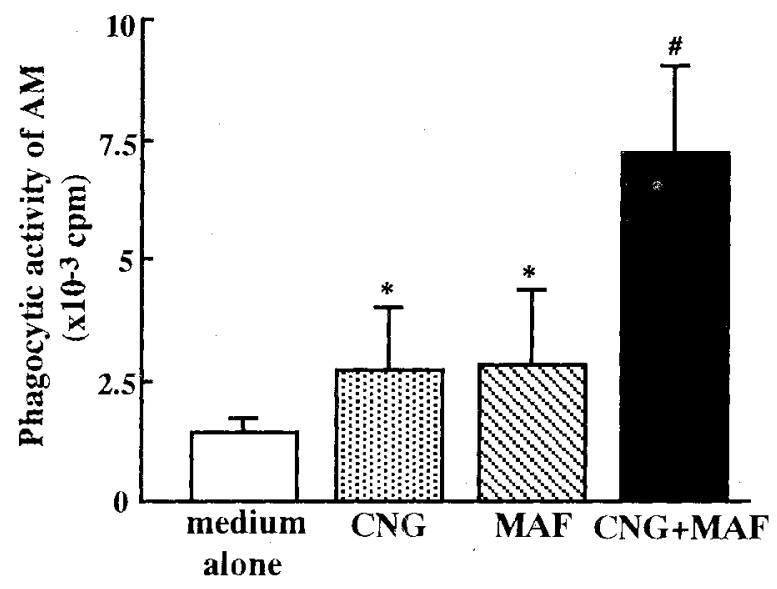

Fig. 5. Fc-receptor expression in AM following in vitro incubation with $\mathrm{CNG}$ and/or MAF.

${ }^{*} p<0.05,{ }^{* *} p<0.01$ (vs. medium alone); ${ }^{\#} p<0.05$ (vs. MAF).

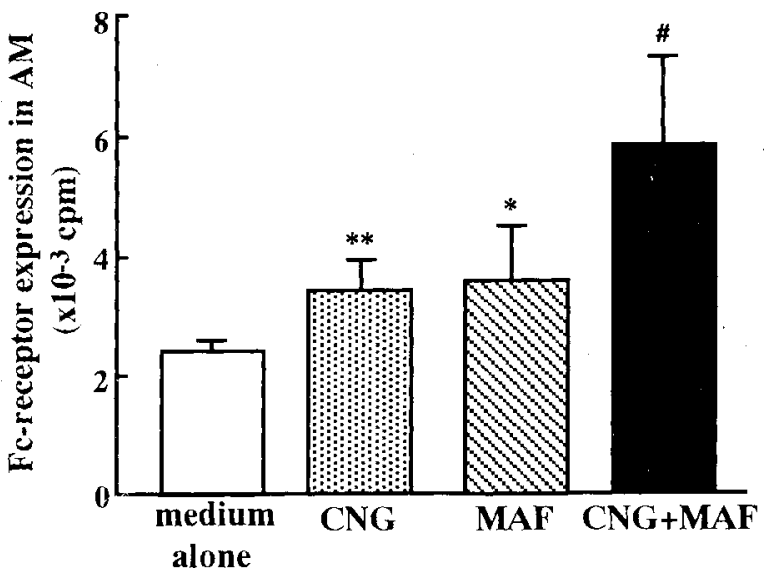

Phagocytosis and Fc-receptor Expression of AM Following the Coculture with $\mathrm{CNG}$ and MAF

Phagocytic activity and Fc-receptor expression of AM against opsonized-SRBC was measured after in vitro incubation with both MAF (1/100 dilution) and CNG $(0.1 \mu \mathrm{g} / \mathrm{ml})$ for 12 hours at $37^{\circ} \mathrm{C}$. The coculture with $\mathrm{CNG}$ and MAF induced the additive increases in both phagocytic activity and Fc-receptor expression in AM 
(Fig. 4 and 5).

\section{Discussion}

CNG prepared from Streptomyces roseosporus enhances the phagocytic activity of AM against opsonizedSRBC. Other investigations have reported that microbial extract such as muramyldipeptides (MDP) ${ }^{4)}$, ubenimex ${ }^{5}$ and forphenicinol ${ }^{6,7)}$ also activate macrophage function. CNG and other microbial extracts may activate macrophage function by a similar mechanisms. As shown in Fig. 2, the enhancement of phagocytic activity of AM against opsonized-SRBC following in vitro incubation with CNG was closely associated with increased expression of Fc-receptor in AM.

MAF prepared from splenic lymphocytes treated in vitro with Con $\mathrm{A}$ for 48 hours is known to enhance macrophage functions as reported previously ${ }^{8,9}$. As shown in Fig. 3, 1/100 dilution of MAF induced the maximum increase of phagocytic activity, which was similar to that observed with CNG treated AM as shown in Fig. 4. The coculture of $\mathrm{AM}$ preparation with $\mathrm{CNG}$ and MAF induced an additive effect on phagocytic activity. This additive stimulation could be due to $\mathrm{CNG}$ and MAF acting by either acting by independent mechanism on the same cells or by acting on different sub-populations of AM by the same mechanisms. Both MAF and CNG increased expression of Fc-receptors in AM (Fig. 5). The coculture with CNG and MAF induced a higher expression of Fc-receptor than either agent alone. Although both agents independently activate the expression of the same receptor, the additive activation again suggests that they act either by independent mechanism on the same cell or by the same mechanism on different sub-populations of cells.

KaWATSU et al. have reported that $\mathrm{CNG}$ inhibits both macrophage function and the secretion of monokine from macrophages in tumor-bearing mice ${ }^{2,3)}$. This does not agree with the results in the study. The discrepancy between KAwATSU et al. and the present studies may be due to the difference in the experimental condition. They used tumor-bearing mice in their experiment. Not only macrophage function but also the secretion of inflammatory cytokines such as TNF- $\alpha$ and IL- 1 were remarkably enhanced during the development of cancer $^{10)}$. In addition, their cytokines promote tumor growth ${ }^{11}$. Therefore, CNG may inhibit macrophage function in tumor-bearing mice due to suppression of tumor growth. In normal mice, $\mathrm{CNG}$ may enhance macrophage function. These results suggest that $\mathrm{CNG}$ is a potent immunomodulator and has the ability to normalize macrophage function depending on the condition of the host. Although CNG and MAF enhanced macrophage phagocytic function in this experiment, it is unclear whether they act independent mechanism on the same cell or the same mechanism on different sub-population of cells. Further work is needed in order to define the detailed mechanism of CNG stimulation of AM function.

\section{References}

1) Yamashita, T.; M. Iijima, H. Nakamura, K. Isshiki, H. Naganawa, S. Hattori, M. Hamada, M. ISHIZUKA \& T. TAKEUCHI: Conagenin, a low molecular weight immunomodulator produced by Streptomyces roseosporus. J. Antibiotics 44: 557 559, 1991

2) Kawatsu, M.; T. Yamashita, M. Osono, M. Ishizuka \& T. TAKEUCHI: T cell activation by conagenin in mice. J. Antibiotics 46: 1687 1691, 1993

3) Kawatsu, M.; T. Yamashita, M. Osono, T. Masuda, M. IsIzUKA \& T. TAKEUCHI: Effect of conagenin in tumor bearing mice antitumor activity, generation of effector cells and cytokine production. J. Antibiotics 46: $1692 \sim 1698,1993$

4) Matter, A.: The effect of muramyldipeptide (MDP) in cell-mediated immunity. Cancer Immunol. Immunother. 6: $201 \sim 210,1979$

5) Ishizuka, M.; J. Sato, Y. Sugiyama, T. Takeuchi \& H. UMEZAWA: Mitogenic effect of bestatin on lymphocytes. J. Antibiotics 33: 653 662, 1980

6) Ishizuka, M.; S. Ishizeki, T. Masuda, A. Momose, T. Aoyagi, T. Takeuchi \& H. Umezawa: Studies on effects of forphenicinol on immune responses. J. Antibiotics 35: $1042 \sim 1048,1982$

7) Okura, A.; H. Arakawa, T. Yoshinari, K. Naito, M. IshizUKa, T. TAKEUCHI \& H. UMEZAWA: Effect of forphenicinol on the production of Ia-positive macrophages in mice with or without L1210 leukemia and on the growth of L1210 in immunized mice. J. Antibiotics 39: 575 580, 1986

8) Moriguchi, S. \& Y. KisHino: Phagocytosis of alveolar macrophages of pyridoxine-deficient rats. J. Nutr. 114: $888 \sim 893,1984$

9) Moriguchi, S.; N. Kobayashi \& Y. Kishino: Effects of vitamin E deficiency on the functions of splenic lymphocytes and alveolar macrophages. J. Nutr. Sci. Vitaminol. 35: 419 430, 1989

10) Alleva, D. G.; C. J. Burger \& K. D. Elgert: Tumor-induced macrophage tumor necrosis factoralpha production suppresses autoreactive $\mathrm{T}$ cell proliferation. Immunobiology 188: 430 445, 1993

11) Wu, S.; C.M. Boyer, R. S. Whitaker, A. Berchuck, J. R. Wiener, J. B. Weinberg \& R. C. BASt Jr: Tumor necrosis factor alpha as an autocrine and paracrine growth factor for ovarian cancer: Monokine induction of tumor cell proliferation and tumor necrosis factor alpha expression. Cancer Res. 53: $1939 \sim 1944,1993$ 